\title{
PRODUÇÃO LITERÁRIA E HISTORIOGRÁFICA MEDIEVAL EM PERSPECTIVAS DECOLONIAIS
}

\section{LITERARY AND HISTORIOGRAPHIC WRITINGS THROUGH DECOLONIAL PERSPECTIVES}

O presente dossiê da Revista Graphos tem a proposta de trazer para o debate dos estudos medievais perspectivas comprometidas em repensar epistemologias e abordagens eurocêntricas e coloniais acerca do Medievo, que foram discutidas no $V$ Seminário de Estudos Medievais na Paraíba, realizado em novembro de 2019, na Universidade Federal da Paraíba.

A decolonialidade do saber, ${ }^{1}$ que se configura na urgência do pensamento decolonial latino-americano nas últimas duas décadas, vem conseguindo ganhar espaço também na medievalística brasileira, e impulsionando a busca por novos conhecimentos sobre o milênio denominado "Idade Média". A invenção de uma "Idade das Trevas", de um tempo intermediário entre duas grandes eras iluminadas - Antiguidade e Renascimento - compõe, entre outras narrativas obscuras, a pauta oculta da Modernidade, que coloca a Europa ocidental, o sistema capitalista, os homens brancos e o cristianismo em uma esfera universalizante, homogênea e central em relação ao resto do mundo.

Observamos, com cada vez mais frequência, que os temas de colóquios, de dossiês, de artigos e de trabalhos acadêmicos vêm privilegiando temas, obras, autore/as do período medieval que estiveram à margem na historiografia tradicional. Destacamos, por exemplo, o tema do XIII Seminário Internacional da Associação Brasileira de Estudos Medievais, "Sobre Margens, Diversidades e Ensino”, realizado em 2019 na Universidade Federal da Bahia, em Salvador, cujos eixos temáticos propostos - Margens/África; Diversidade/Gênero; Ensino buscaram dar ênfase a pesquisas ainda pouco exploradas pelos estudos medievais ${ }^{2}$.

O impacto das discussões suscitadas neste evento reverberou, sem dúvida, nos diálogos e publicações entre os membros da ABREM, no ano em curso, como aponta, em particular, o título do dossiê organizado pelos professores Luciano Vianna, Otávio Pinto e Rodrigo Bonaldo, Decolonizar a Historiografia Medieval: Introdução à História da Historiografia Medieval -

\footnotetext{
${ }^{1}$ Conceito central das teorias decoloniais propostas pelos teóricos da América andina do projeto do grupo latinoamericano Modernidade/Colonialidade, como Aníbal Quijano, Walter Mignolo, Enrique Dussel, María Lugones, Catherine Walsh, Immanuel Wallerstein, Edgardo Lander.

${ }^{2}$ Os textos das mesas-redondas do evento foram publicados em 2020 na Signum, revista da ABREM. A referência completa desta publicação pode ser conferida no final desta Apresentação.
} 
Novas Abordagens, publicada em junho de 2020 na Revista História da Historiografia. No mesmo rumo, estão direcionadas as palestras propostas no I Ciclo Virtual de Idade Média no Nordeste, organizado pelos grupos Leitorado Antiguo (UPE), LETHAM (UFBA), LEOM (UFPE), Spatio Serti (UPE) e VIVARIUM (UFAL). “Aprender com a Idade Média: notas sobre a descolonização do medievo na escola básica", "Uma Idade Média descolonizada no nordeste brasileiro: os romances de Ariano Suassuna" e "Onde vivem os monstros: usos do passado e ensino de História Medieval na era Bolsonaro" foram alguns dos temas discutidos por medievalistas convidados/as para esse ciclo virtual e, indiscutivelmente, revelam o interesse pela prática decolonial no seio da medievalística brasileira atual.

Embora tenha se intensificado neste último ano o uso do termo e das perspectivas decoloniais nos estudos medievais, o pensamento decolonial vem orientando algumas iniciativas nas últimas décadas, a exemplo dos eventos promovidos pelo Núcleo Interdisciplinar de Estudos Medievais Meridianum, coordenado pela profa. Aline Dias da Silveira, na UFSC, ou ainda os seminários organizados pelo grupo Christine de Pizan (CNPq/UFPB/UnB): "As primaveras medievais" e os "Seminários de Estudos Medievais na Paraíba"3.

\section{Sobre o V Seminário de Estudos Medievais na Paraíba}

A V edição do Seminário bianual da linha de pesquisa Estudos Medievais do PPGL foi organizada por três grupos de pesquisa: Grupo Christine de Pizan, coordenado pelas professoras Luciana Deplagne (UFPB) e Cláudia Brochado (UnB), Gradalis, coordenado pelo professor Guilherme Queiroz de Souza (UFPB) e Estudos Coloniais Latino-americanos, coordenado pelo professor Alfredo Cordiviola (UFPE). Com uma proposta interdisciplinar, o seminário teve por tema "Idade Média: perspectivas multidimensionais" e centralizou o debate em três dimensões: dimensão espacial, dimensão temporal e dimensão de gênero. Para cada dimensão proposta um/a especialista interveio, trazendo discussões de relevância na articulação dos estudos medievais com o pensamento decolonial.

Para a dimensão espacial, o Prof. Dr. José Rivair Macedo (UFRGS) proferiu a conferência intitulada "O eixo transaariano: circulação de pessoas, ideias e bens entre o Magrebe e a Bacia do Níger (séculos XIV-XV)"; para a dimensão temporal, acolhemos a conferência "A invenção da América: figurações do medieval e do moderno", proferida pelo Prof. Dr. Alfredo Cordiviola (UFPE); e, para pensar a dimensão de gênero, a pesquisadora Dra. Ria Lemaire (Université de

\footnotetext{
${ }^{3}$ Estas são apenas algumas iniciativas de grupos de pesquisa lideradas por sócios da ABREM.

Revista Graphos, vol. 22, n 3, 2020 | UFPB/PPGL | ISSN 1516-1536
} 
Poitiers) propôs uma homenagem à dramaturga paraibana Maria de Lourdes Nunes Ramalho (1920-2019), reconhecida por seu teatro multicultural, que buscava pôr em valor, em suas premiadas peças teatrais, as raízes ibéricas e da cultura popular, bem como o protagonismo feminino e contestatário de práticas coloniais opressoras e patriarcais.

No presente dossiê, foram reunidas algumas das contribuições de palestrantes de mesasredondas e minicursos, com foco na conexão multidisciplinar dos estudos literários e historiográficos com a decolonialidade do saber acerca dos estudos medievais.

\section{Idade Média: perspectivas multidimensionais}

No artigo que abre este dossiê, ${ }^{4}$ a medievalista holandesa Ria Lemaire parte de sua experiência de peregrinação no Caminho de Santiago para refletir questões relacionadas à construção de um "Patrimônio" de tradições androcêntricas na cultura medieval. Ao longo do percurso várias pegadas de um caminho ancestral do culto da Deusa-Mãe-Terra, deusa da fertilidade e fecundidade, foram apontando como, desde o século IX, se deu a transformação da "narrativa-mito" sobre o caminho até o apagamento do "Matrimônio" nessa tradição e em outros rituais da Idade Média. A partir dessa experiência, a pesquisadora identifica os fundamentos misóginos da historiografia oficial e da epistemologia colonial e recupera epistemologias silenciadas, como é o caso do termo Matrimônio: "Conjunto dos bens materiais e imateriais, transmitido, em linha materna, das mães para as filhas e das mulheres para as jovens gerações de mulheres”. Através de uma prática decolonial, o texto, composto de sete densos tópicos, examina um dos grandes monumentos da literatura ibérica medieval, o Cancioneiro das 412 Cantigas de Santa Maria, atribuídas ao rei Afonso X, o Sábio, rei de Galiza, Leão e Castela (1252-1284) e o papel desse processo de apropriação dos matrimônios poético e cultural.

O artigo seguinte, de autoria das pesquisadoras Maria Vásquez Gusmán e Ana Suárez Miramón, também segue pelas veredas arqueológicas de uma tradição feminina de cânticos/poemas pertencentes a um matrimônio ancestral. Baseadas nos estudos de Janés (2015), Andiñach (2010), Martín Ortega (2010), Botta (1997), entre outros, as autoras refletem sobre as possíveis origens e fontes dos poemas em voz feminina atribuídos a Salomão em Cânticos dos cânticos, no Antigo Testamento. Através dessa discussão sobre o protagonismo

\footnotetext{
${ }^{4}$ Este artigo faz parte de uma trilogia de reflexões onde a autora desenvolve o conceito de Patrimônio/Matrimônio. Ver referência completa no final desta Apresentação.
}

Revista Graphos, vol. 22, n 3, 2020 | UFPB/PPGL | ISSN 1516-1536 
da voz feminina nestes fragmentos poéticos encontrados na Bíblia, o artigo investiga as conexões da obra Cântico Espiritual do poeta espanhol San Juan de la Cruz (1542-1591) com o Cântico dos cânticos. Para as autoras, o lugar central da voz feminina na obra do poeta relaciona-se também com a presença das mulheres em sua vida, em especial, Ana de Jesus e Teresa d'Ávila, tornando sua poesia muita próxima da mística feminina e toda a força erótica na expressão da experiência de união mística com o divino.

A mística feminina é igualmente objeto de análise do artigo de Maria Graciele de Lima e Fernanda Cardoso. As autoras analisam as obras The Book of Margery Kempe, da mística inglesa Margery Kempe (século XV) e o Libro de las Fundaciones, da espanhola Teresa d'Ávila (século XVI), tendo como foco a peregrinação como marca de seus escritos. O artigo se propõe a inserir as místicas Margery Kempe e Teresa d'Ávila dentro de uma tradição de peregrinas e andarilhas, como Maria Madalena (século I), Egéria (século IV) e Maria Egipcíaca (c. 344-422), dando ênfase aos registros das viagens deixados em obras de peregrinas escritoras, desde O Itinerário de Egéria (Itinerarium Egeriae ou Itinerarium Peregrinatio ad loca sancta), do século IV. Analisando trechos das obras referidas, o artigo mostra como as duas escritoras "trilharam seus longos e significativos caminhos e escreveram sobre os mesmos".

Já o artigo de Maria Simone Marinho Nogueira apresenta e analisa o livro de Marguerite Porète, Espelho das almas simples e aniquiladas e que permanecem somente na vontade e no desejo do amor, devido ao qual a escritora mística foi condenada à fogueira da Inquisição em 1310 e queimada na praça de Grève, em Paris. Ao analisar o traço transgressor dessa obra escrita em língua vernácula [médio-francês (picardo)], Nogueira apresenta como o embate das protagonistas alegóricas, Razão (Igreja), Alma (o ser humano), se configura em reflexões críticas de Marguerite Porète, enquanto mulher e representante da livre espiritualidade, acerca dos poderes e hierarquias da instituição igreja. Articulando os conceitos de "não-lugar", "sujeito", "autoria feminina", Nogueira demonstra como essa obra mística medieval oferece elementos textuais e intertextuais para se falar de uma escrita de si.

Os próximos artigos tratam de mulheres leigas e seus legados fora do âmbito religioso, do século XI ao XV. A pesquisadora Karine Simoni, uma das tradutoras para o português do tratado ginecológico “As doenças das mulheres”, escrito pela médica Trotula, nos apresenta um pouco deste projeto tradutório. Após discorrer sobre o contexto de produção da obra, a importância que as traduções do árabe tiveram na evolução do saber médico na Europa, os diferentes manuscritos do tratado que circularam durante os últimos séculos que antecederam a primeira edição imprensa, as fontes médicas utilizadas por Trotula e a polêmica em torno da 
autoria do tratado na modernidade, Simoni desenvolve sua proposta de elencar as contribuições do tratado de Trotula para as mulheres de sua época e sua importância ainda para os dias atuais. Cinco lições são destacadas pela pesquisadora: a cura pelas plantas, os preceitos de Hipócrates e Galeno, a defesa da higiene e da boa alimentação e o cuidado do organismo em sua relação com o social.

O sexto artigo do dossiê põe em cena as narrativas em verso de uma importante escritora do século XII, Marie de France. Rosiane Xypas analisa em duas coletâneas do gênero "lais" a representação do amor feminino na Literatura. Em um primeiro momento, a pesquisadora define o gênero lais e destaca sua contribuição na introdução do conceito do Amor Cortês na Literatura medieval, bem como na Matéria da Bretanha. Para a realização do estudo comparativo, foram analisadas vinte e três lais, sendo onze nos Lais dos Bretões (2013) e doze nos Lais de Maria de França (2001), considerando o perfil das personagens femininas e os espaços amorosos das narrativas. A autora conclui com a seguinte observação: "Considerando que essas narrativas eram passadas de geração em geração, sua influência repercute até os dias atuais através de idealizações românticas observadas na cultura literária e cinematográfica".

Finalizamos esse bloco de sete textos com o interesse voltado para a dimensão de gênero, com o artigo do pesquisador Pedro Carlos Louzada Fonseca. A proposta do trabalho é revisitar a tradição misógina que provocou a escritora Christine de Pizan a escrever a obra $L a$ Cité des Dames, em 1405. Ao trazer esta obra de autoria feminina para discussão sobre as relações de gênero na Idade Média, o pesquisador diz que sua intenção foi a de "investigar/desconstruir alguns aspectos da construção da realidade feminina no âmbito de configurações ideológicas e politicamente apresentadas na Idade Média”. Para tanto, toma como uma das fundamentações do seu artigo, o estudo da filósofa feminista Simone de Beauvoir para contribuir no balanço crítico sobre a construção histórica de uma tradição misógina desde a Antiguidade, passando pelas auctoritas medieval, até tempos mais recentes, e por que não dizer atuais?

Outro aspecto dos artigos reunidos no dossiê é a dimensão espaço-temporal. Aqui, encontramos inicialmente o trabalho de José Alberto Miranda Poza, que investiga o Medievo ibérico, com ênfase em suas múltiplas relações políticas, sociais e culturais. Seu objetivo é compreender a natureza de algumas manifestações literárias, muitas das quais articulavam tradições orientais e ocidentais. Nesse novo contexto, escritos como as Jarchas, o Libro de Calila e Dimna, o Libro de Apolonio e El Conde Lucanor floresceram em versões adaptadas. Trata-se de uma Idade Média que não se restringe às fronteiras do mundo latino ocidental; na 
verdade, destacam-se aquilo que denomina de "resíduos culturais", elementos trocados e transmitidos do Oriente ao Ocidente.

A ideia de refletir sobre as influências medievais para além do século XV, tradicionalmente entendido como o último suspiro dessa temporalidade, é trabalhada por Juan Pablo Martín Rodrigues. Ele se debruça sobre a chamada Controvérsia de Valladolid (1550), que opôs dois célebres juristas e teólogos espanhóis: Juan Ginés de Sepúlveda e Bartolomé de las Casas. Seu propósito é destacar a presença de um pensamento filosófico medieval nessa polêmica, que tinha como finalidade debater a legitimidade de uma guerra conduzida contra os ameríndios. Para tanto, o autor argumenta ter encontrado indícios de uma filosofia escolástica envolvendo a contenda.

Em seguida, temos o artigo de Aurora Cardoso de Quadros, que pretende examinar como questões ideológicas, sobretudo de natureza religiosa (católica), impactaram no processo de colonização do Brasil no século XVI. Para isso, investiga um caso em particular, o protagonismo do padre jesuíta José de Anchieta, cuja atuação entre os nativos possibilitaria observar uma violência simbólica, algo que seria típico do contexto de expansão do catolicismo quinhentista. A autora argumenta que a produção escrita jesuítica tem uma relação direta com a evangelização e com os sermões dos pregadores medievais, seus valores e códigos morais.

Depois, encontramos o texto de Juan Ignacio Jurado-Centurión López, que examina o imaginário medieval à luz da teoria do Novo Medievalismo. Para tanto, recorre às composições literárias, prestando atenção em quatro temáticas: utopia, cortesia, papel da mulher e ideal cavaleiresco. À luz daquela teoria, o autor salienta a importância de uma visão poliédrica de investigação que, com o auxílio de outras disciplinas (como a História, Sociologia e Paleografia), possibilitaria uma renovada compreensão dessas ricas manifestações literárias.

Por fim, chegamos ao artigo de Carlile Lanzieri Júnior, que adota uma posição mais horizontal e menos hierárquica para analisar uma relação na Europa ocidental (séculos XI-XII) estabelecida entre mestre e discípulo, respectivamente, Anselmo de Bec e Guiberto de Nogent. Tais autores são pensados a partir da metáfora "homens catedrais", já que conservaram e acumularam experiências. Aprenderam e ensinaram. Transmitiram saberes. Segundo o historiador, devemos ultrapassar a noção petrificada e teleológica de abordagem; impõe agora entender aqueles atores sociais em toda a complexidade da época em que viveram e escreveram; homens que, nos âmbitos público ou privado, revelaram contradições e aflições.

Esperamos que os artigos deste dossiê da Revista Graphos, "Idade Média: perspectivas multidimensionais", estimulem renovadas reflexões sobre essa fascinante temporalidade, 
provocando inquietações, perguntas e problematizações antes jamais imaginadas. Sem isso, nenhum conhecimento pode avançar.

Boa leitura!

João Pessoa, 18 de dezembro de 2020

Guilherme Queiroz de Souza (UFPB)

Luciana Calado Deplagne (UFPB)

Ria Lemaire (Université de Poitiers)

Organizadores do Dossiê

\section{Referências}

BONALDO, Rodrigo Bragio; PINTO, Otávio Luiz Vieira; REZAKHANI, Khodadad; VIANNA, Luciano José. Decolonizar a historiografia medieval: Introdução à História da Historiografia Medieval - Novas Abordagens. História da Historiografia: International Journal of Theory and History of Historiography, v. 13, n. 33, p. 19-37, 2020.

DEPLAGNE, Luciana. A contribuição dos escritos de mulheres medievais para um pensamento decolonial sobre Idade Média. Signum: revista da ABREM, vol. 20, n. 2, p. 24-56, 2019.

LANDER, Edgardo (org.). A Colonialidade do Saber: eurocentrismo e ciências sociais. Buenos Aires: CLACSO Livros, 2005.

LEMAIRE, Ria. Patrimônio e Matrimônio I: proposta para uma nova historiografia da cultura ocidental. Educar em Revista, n. 70, p. 17-33, 2018.

LEMAIRE, Ria. Patrimônio e Matrimônio II: Repensar a historiografia das literaturas nacionais. Revista de Estudos Linguísticos e Literários, Salvador, n. 59, p. 54-72, 2018.

MIGNOLO, Walter. Colonialidade: o lado mais escuro da modernidade. Revista Brasileira de Ciências Sociais, São Paulo, v. 32, n. 94, p. 01-17, 2017.

MUNIZ, Márcio R. Coelho. Dossiê: Sobre margens, diversidades e ensino na/da Idade Média. Signum: revista da ABREM, v. 20, n. 2, p. 4-10, 2019.

QUIJANO, Aníbal. Colonialidade do poder, Eurocentrismo e América Latina. In: LANDER, Edgardo (org.). A Colonialidade do Saber: eurocentrismo e ciências sociais. Buenos Aires: CLACSO Livros, 2005, p. 227-278. 